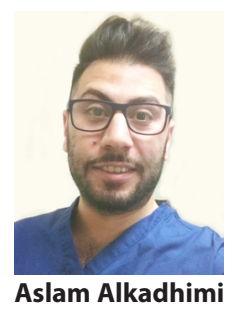

Mohammad Owaise Sharif

\title{
Orthodontic Retention: a Clinical Guide for the GDP
}

Abstract: Retention is normally required after active orthodontic tooth movement in order to maintain tooth position and minimize the effects of age-related changes to the dentition. The aim of this article is to define stability, retention and relapse with reference to the literature and to review the evidence with regards to clinical effectiveness of different types of fixed and removable retainers and wear regimens, with emphasis on systematic reviews and Randomized Controlled Trials (RCTs). Furthermore, to discuss the general dental practitioner's role and responsibility in managing patients after active orthodontic treatment.

CPD/Clinical Relevance: It is common practice for orthodontists to review patients for one year after active orthodontic treatment. Beyond this period, monitoring of the patient's long-term retention is often carried out in general dental practice. This paper provides an overview of orthodontic retention, including retainer types, wear regimens and a discussion of the common problems associated with retainers and advice on management.

Dent Update 2019; 46: 848-860

Orthodontic relapse can be disheartening for both patient and clinician alike; it is therefore common practice to provide retainers to maintain tooth position after active orthodontic treatment. Relapse was defined by the British Standards Institute (BSI) in 1983 as 'The return, following correction, of the original features of the malocclusion. A more contemporary definition states that 'it is unfavourable change(s) from the final tooth position at the end of orthodontic treatment.' This latter definition encompasses the notion of positional changes of the dentition that are seen to occur with advancing age. ${ }^{2}$ Orthodontic retention can be defined as 'the

\footnotetext{
Aslam Alkadhimi, BaBDentSc(Hons), MFD (RCSI), Orthodontic Specialist Registrar (email: aslam.alkadhimi.17@ucl.ac.uk) and Mohammad Owaise Sharif, BDS(Hons), MSc, MOrth, RCS Ed, FDS(Ortho) RCS Eng, FHEA, Clinical Lecturer/Honorary Consultant in Orthodontics, University College London, Eastman Dental Institute, London, UK.
}

phase of orthodontic treatment following completion of the desired tooth movement, focused solely on maintaining the finished treatment result and preventing relapse.'3 Retainers can be either removable or fixed. In practice a combination of the two is often utilized. Although many variations of retainers are available, the Hawley retainer (HR) and the vacuum-formed retainer (VFR)/ thermoplastic retainer are two of the most commonly used removable retainers.

This paper aims to explore the common types of fixed/removable orthodontic retainers in depth and outline some of the common problems associated with retainers that can be encountered by the GDP.

\section{Rationale for retention}

1. Reorganization of periodontal apparatus Reitan, in 1967 and Edwards, in 1988, demonstrated that reorganization of the gingival and periodontal tissues occurs following orthodontic tooth movement. ${ }^{4,5}$ This reorganization time varies according to fibre type and can take up to a year. During this period, retainers act to resist 'physiological relapse'.

\section{Prevention of unwanted tooth movement resulting from growth changes Prolonged retention of the lower labial segment, until the end of facial growth, may reduce the severity of future lower incisor crowding. ${ }^{6}$}

\section{Reducing relapse tendency of teeth that have been moved to an inherently unstable position}

A 'zone of equilibrium' exists when the forces derived from the periodontal and gingival tissues, the orofacial soft tissues, the occlusion and post-treatment facial growth and development are in balance. ${ }^{7}$ If teeth are moved out of this zone, there will be a tendency for relapse. This is often referred to as 'true relapse.' Examples include increasing intercanine width, ${ }^{8}$ significant alteration of the archform, ${ }^{9}$ change in the intermolar 


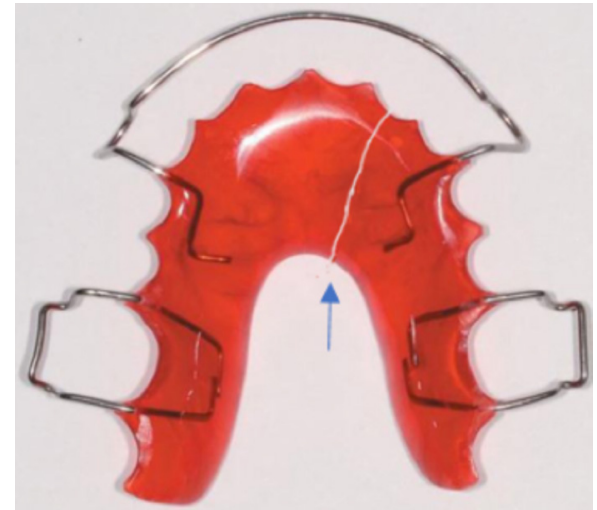

Figure 1. Clean break of the acrylic baseplate. Can be repaired chairside with cold-cured acrylic. Alternatively, an impression of the arch can be sent to the lab for indirect repair.

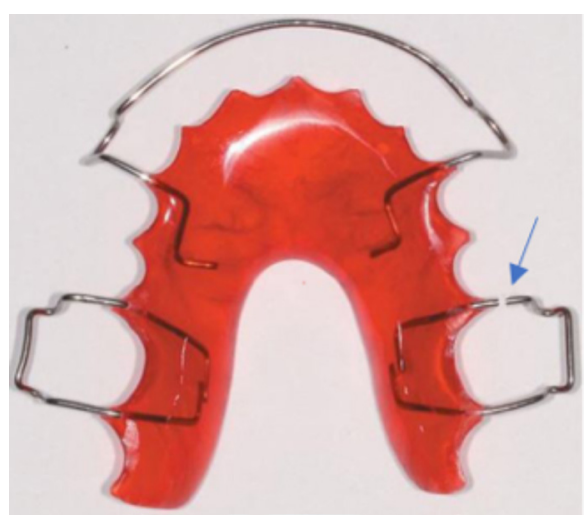

Figure 2. Breakage of Adam's clasp due to cyclic fatigue. A new impression of the arch should be taken and sent to the lab for construction of a new retainer.

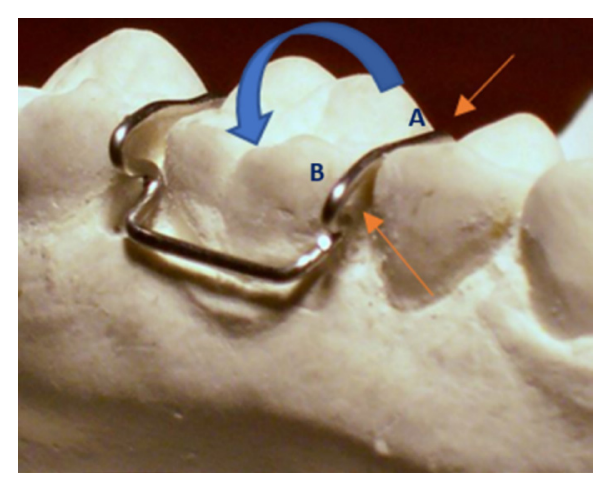

Figure 3. To tighten the Adam's clasp, hold the clasp with pliers (eg Adam's pliers) at either point $A$ or $B$ and bend inwards so that the arrowheads engage the undercuts.

width $^{10}$ and change in labio-lingual position of lower incisors. ${ }^{11}$ This could be considered an iatrogenic cause of relapse since the teeth are actively placed in a position considered

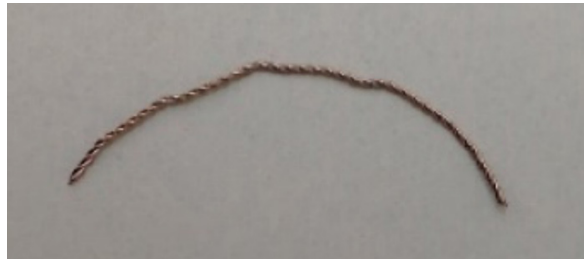

Figure 4. An example of TwistFlex wire fabricated chairside and closely adapted to lingual surface of mandibular anterior teeth utilizing a sectional model.

to be unstable., ${ }^{7,12}$ In these circumstances, indefinite retention may be required to resist relapse.

\section{Age-related changes}

These changes are normal physiological changes but might be confused with relapse by a patient who has received earlier orthodontic treatment. ${ }^{12,13}$ Some of the normal maturational changes to be expected include:

A decrease in arch length after adolescence;

- Intermolar width increasing until age of 13 years then becoming static with some reduction in females thereafter;

- Arch length and intercanine width all increasing until 13 years then reducing, especially in females

- A small decrease in overjet and overbite.

\section{Common types of removable retainers}

A variety of removable retainers are available. Table 1 summarizes the common removable retainers, including typical design features. The most frequently utilized removable retainers are Hawley and thermoplastic vacuum-formed retainers (VFRs).

\section{Broken/ill-fitting removable retainers}

Removable acrylic retainers are often easy to repair where the breakage is minor/there is a clean break of the acrylic. It is good practice to take an impression of the arch with the retainer in situ and send this to the laboratory for repair (Figure 1).

If there is a break in the wirework, good practice requires remake of the retainer, as soldering the wirework will only be a short-term temporary solution (Figure 2). Retention of the appliance should always be checked on review and clasps, if poorly retentive, can be tightened easily, as shown in Figure 3. Replacement is required for broken VFRs.

\section{Fixed retainers}

Treatment of certain malocclusions are particularly prone to relapse. These are detailed in Table 2. In these cases, fixed retainers are often utilized. Table 3 summarizes the advantages and disadvantages of fixed retainers.

In some cases, fixed retainers

can be combined with removable retainers, so called 'dual retention'. The rationale for dual retention is to allow for breakage in the fixed retainer, which can go unnoticed by the patient; in addition this maintains posterior alignment.

In the lower arch, fixed retainers are usually placed on the six lower anterior teeth and, in the upper arch, they often span all four incisors.

In some cases, modifications might be indicated, for example extension to the lower premolars occlusally, where the canines are severely rotated before treatment or there was space/step between the premolar and canine. Upper fixed retainers can be extended to canines in cases of alignment of significantly palatal displaced canines to account for their tendency to relapse.

\section{Fabrication and placement of fixed retainers}

Fixed retainers can either be made directly at the chairside by bending a suitable stainless steel wire to fit the relevant lingual/palatal surfaces, or in the laboratory utilizing a model created from an impression of the anterior teeth (Figure 4). To fit a bonded retainer, the tooth surface should be thoroughly cleaned. A dry field is maintained after etching, and the wire should be held passively in position while using a flowable composite resin as the adhesive. It is essential that bonded retainers are passive when fitted and there should be no spaces between the wire and tooth surface. The retainer can then be held and secured with dental floss, elastic bands or an occlusal jig, against the lingual/palatal surface of teeth and flowable composite 


\section{Orthodontics}

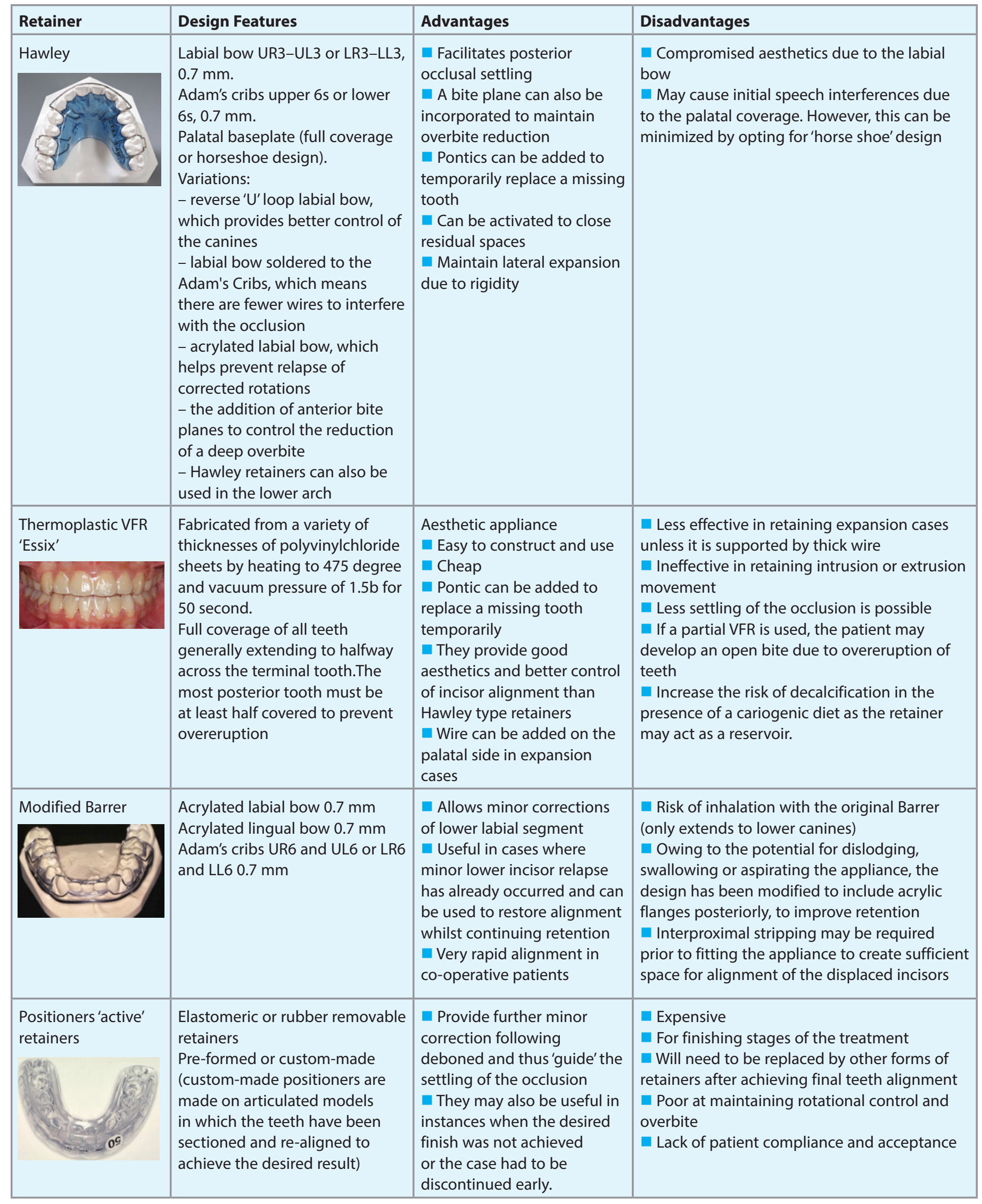




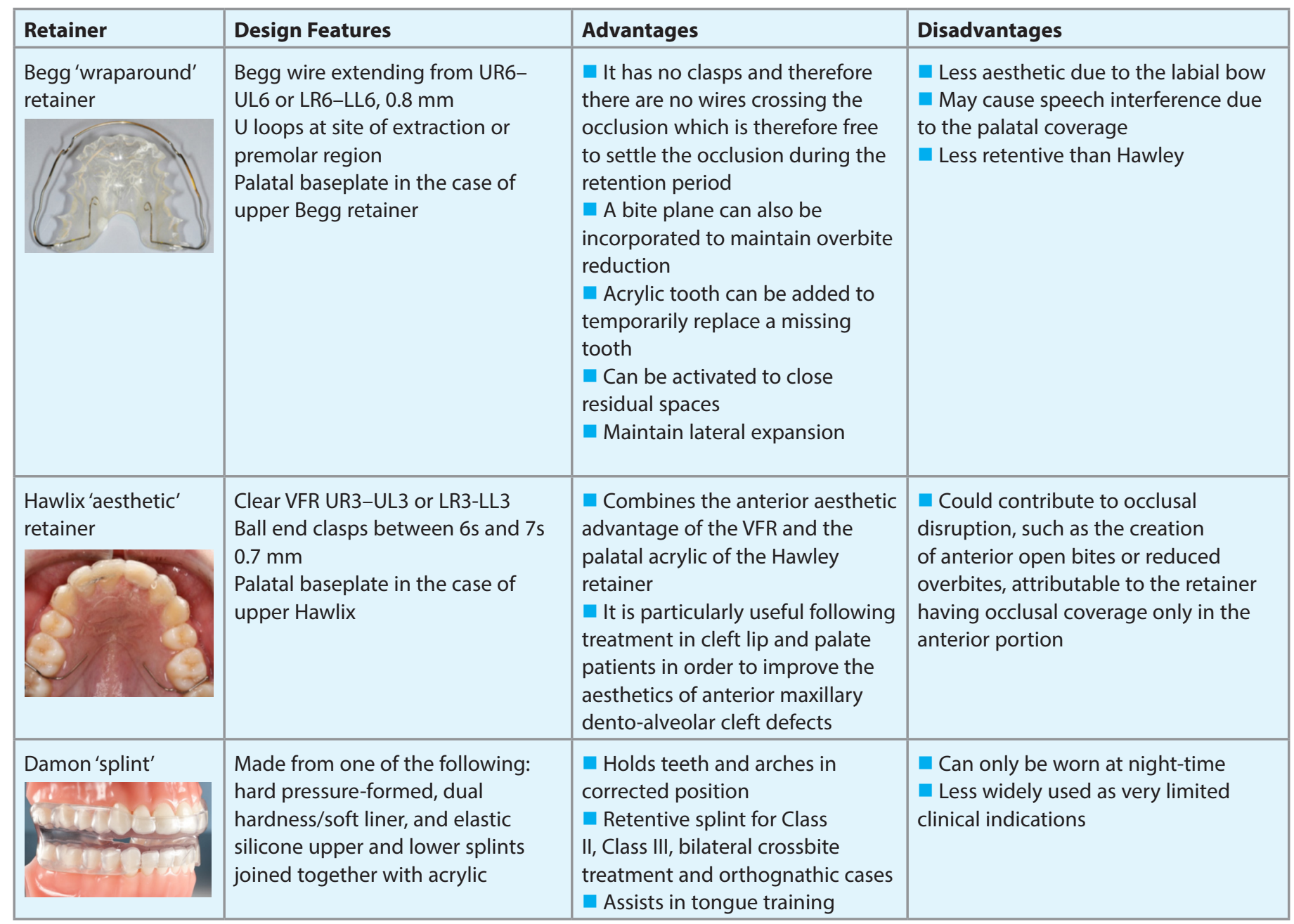

Table 1. Different types of removable retainers showing the most common design features. All the wires described above are made from stainless steel.

Severe rotations which have been corrected

If lower incisors have been proclined by $>2 \mathrm{~mm}$

Teeth moved out of the zone of equilibrium

Combined periodontal/orthodontic treatment where the adequacy of support for the teeth is in doubt

Diastemas or closure of generalized spacing

- Severely displaced teeth, particularly palatal canines

Non-surgically treated anterior open bite cases with incisor extrusion

- Impacted teeth which have been individually extruded and aligned

- Corrected anterior crossbites where there is minimal overbite to retain the correction naturally

- Teeth with no opposing tooth (to prevent overeruption)

Cleft Lip/Palate patients. In these cases bonded retainer is combined with removable appliance to maintain transverse relationship

Extraction space closure in adults

Alteration in intercanine width

Table 2. Clinical scenarios in which one may wish to consider fixed retainers. 


\section{Orthodontics}

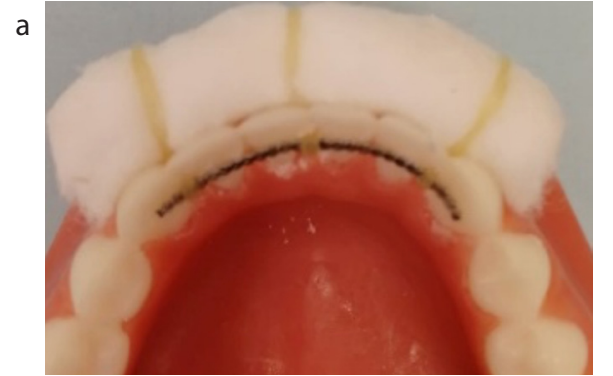

b

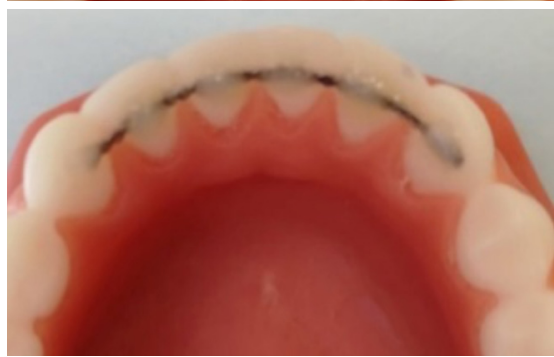

C

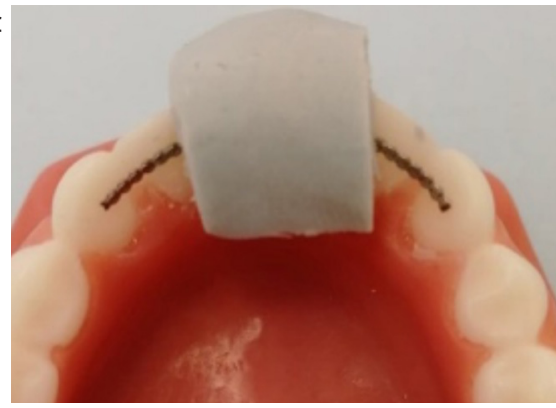

d

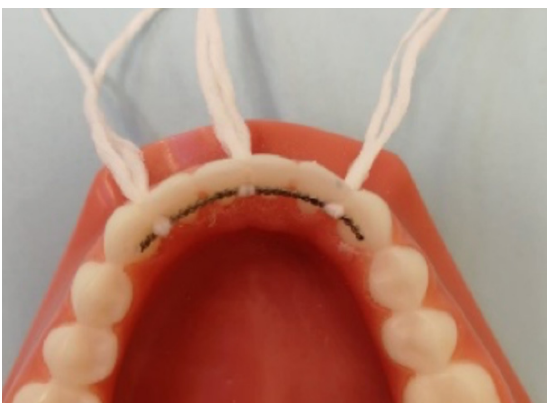

Figure 5. Different methods of securing the wire before bonding. (a) Threading the retainer through elastics and cotton roll on labial side. (b) The retainer was bonded without utilizing any auxiliary methods. (c) Using a transfer jig and (d) securing the retainer with dental floss through contact points.

added and light cured (Figure 5). Any activation of the retainer wire during bonding can cause unwanted tooth movement. ${ }^{15}$

\section{Classification}

\section{Banded retainers}

Bands placed on the lower premolars with a

\begin{tabular}{|c|c|}
\hline Advantages & Disadvantages \\
\hline Easy and well tolerated by the patient & Their placement is time-consuming \\
\hline Unlikely to compromise on aesthetics & Technique-sensitive \\
\hline Unlikely to interfere with speech & $\begin{array}{l}\text { Interference with the occlusion, especially in } \\
\text { cases with increased overbite }\end{array}$ \\
\hline $\begin{array}{l}\text { Less compliance dependent than } \\
\text { removable retainers }\end{array}$ & $\begin{array}{l}\text { Gingival/periodontal disease and caries may } \\
\text { develop due to plaque accumulation }\end{array}$ \\
\hline $\begin{array}{l}\text { It may reduce the risk of development } \\
\text { of late lower labial segment crowding }\end{array}$ & May prevent settling of the occlusion \\
\hline $\begin{array}{l}\text { Allow some physiological movement of } \\
\text { the teeth }\end{array}$ & Do not retain transverse expansion \\
\hline Retain derotations well & High failure rates $23 \%{ }^{14}$ \\
\hline $\begin{array}{l}\text { Can be fabricated indirectly in the lab } \\
\text { therefore reducing chairside time and } \\
\text { complexity of fabrication }\end{array}$ & $\begin{array}{l}\text { Fixed retainers can fail without the patient } \\
\text { realizing - this may result in unwanted tooth } \\
\text { movement }\end{array}$ \\
\hline $\begin{array}{l}\text { No evidence of increased periodontal } \\
\text { or enamel damage }\end{array}$ & $\begin{array}{l}\text { A back-up removable retainer should also } \\
\text { be supplied to the patient to preserve tooth } \\
\text { position if the fixed retainer fails. }\end{array}$ \\
\hline
\end{tabular}

Table 3. Advantages and disadvantages of fixed retainers.

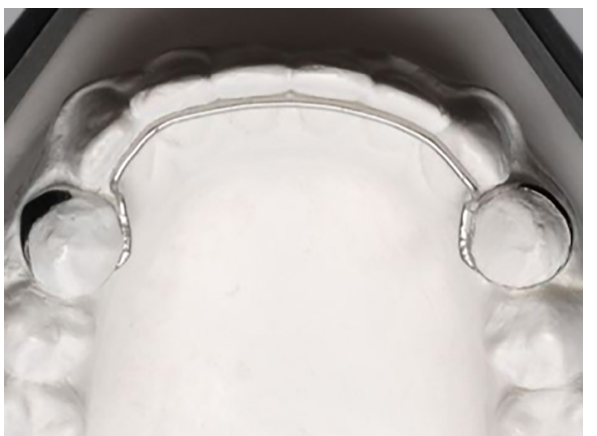

Figure 6. An example of banded retainer that extends from first premolars used historically to maintain the inter-premolar and intercanine widths.

connecting soldered, heavy archwire (0.030"), closely adapted to the lower labial segment above the cingulum of lower anterior teeth (Figure 6). This type of retainer is now rarely used.

\section{Bonded retainers}

Numerous wire materials have been proposed but the multi-stranded wire, introduced by Björn Zachrisson in $1982^{16}$ is now the gold standard. ${ }^{17}$

Flexible retainers bond on the lingual/palatal surface of each individual tooth and allow physiological tooth movement. The materials used are:

'TwistFlex' (Figure 7a): Multi-stranded wire is round in cross-section and formed from strands that are twisted, made from 0.015", $0.0175^{\prime \prime}, 0.0195^{\prime \prime}$ or even $0.0215^{\prime \prime}$ stainless steel strands.

Round, sandblasted stainless steel wire, $0.030 "-0.032$ " in diameter.

口 'OrthoFlexTech' (Figure 7b) braided chain made from stainless steel (often for direct placement)

Reinforced fibres (often for direct placement). The fibreglass strips are soaked in composite and bonded to prepared enamel surface. This technique has the advantage of reducing the bulk of the retainer. However, these retainers tend to 
a

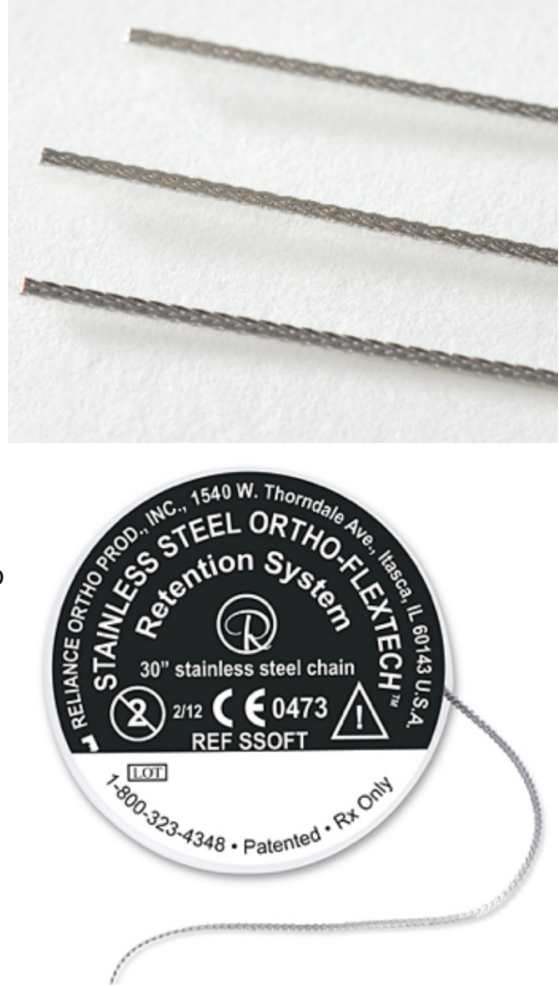

Figure 7. Examples of (a) 'TwistFlex' and (b) 'OrthoFlexTech',

fracture more frequently.

Rigid retainers (bonded on canines only, touching but not bonded to lower incisors) are made from $0.30^{\prime \prime}-0.32$ " SS bar. Bearn considered the following to be indications for placement of a bonded canine to canine retainer: ${ }^{17}$

- Severe pre-treatment lower incisor crowding or rotation;

- Planned alteration in the lower intercanine width;

After proclination of the lower incisors during active treatment;

- After non-extraction treatment in mildly crowded cases;

After correction of deep overbite.

Multi-stranded wires are a popular choice and some advantages include:

1. The irregular surface offers increased mechanical retention for the composite without the need for the placement of retentive loops;

2. The flexibility of the wire allows physiologic movement of the teeth, even when several adjacent teeth are bonded; ${ }^{17}$

3. Less failure rate than round wire because of the flexibility. Al-Nimri et al, however, found
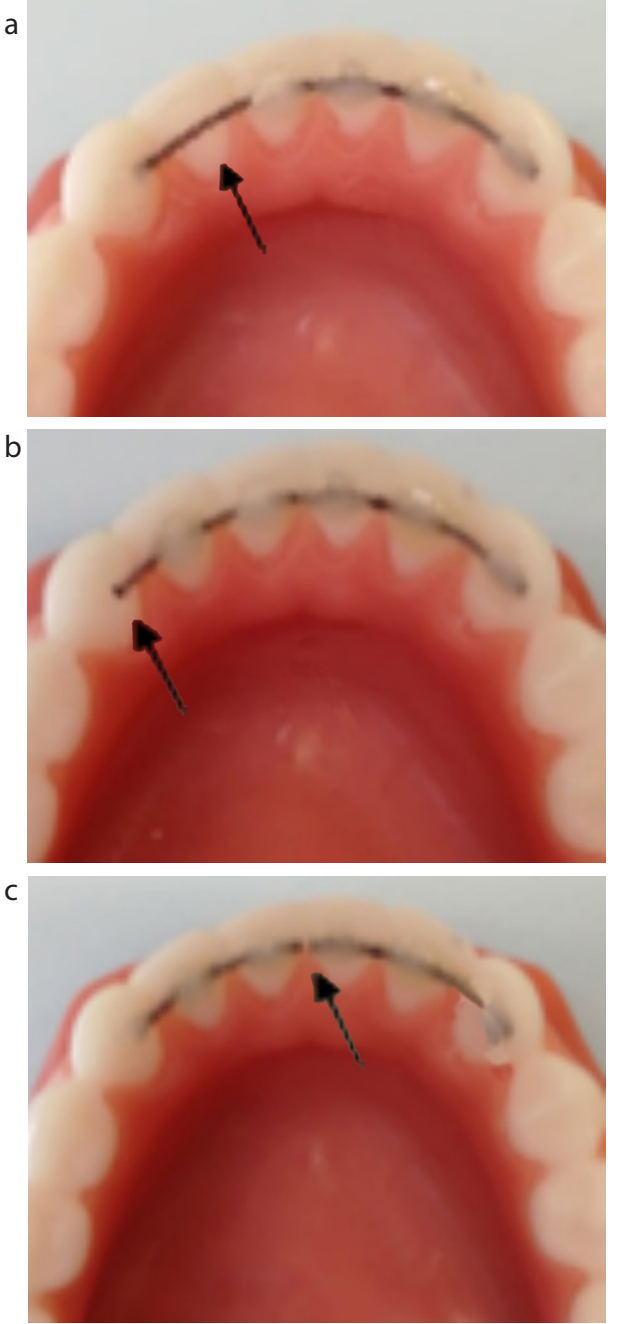

Figure 8. Examples of common problems with bonded retainers. (a) Retainer debonded at one of the incisors. (b) If a terminal tooth had debonded, then bonding the tooth again can be done by simply preparing the surface as usual. (c) A fractured retainer needing to be replaced with a new one following the usual bonding protocol.

no difference between multistrand or round wire except more plaque accumulation with the former. ${ }^{18}$

\section{Bonded retainers: monitoring and managing problems}

Fixed retainers should be reviewed periodically and maintained or repaired where necessary. They should be checked thoroughly at least annually to ensure that the composite and wire components are intact, with no distortions, and that there is no excessive calculus build-up around the retainer. Any calculus build-up should be removed and the need to use Waterpiks, Superfloss, TePe brushes or similar oral hygiene aids should be reinforced regularly.

The sites of retainer failure

include:

Wire-composite interface;

Composite-enamel interface;

Wire fracture.

If the composite is lost completely from one tooth, then simply cleaning the tooth and replacing the lost composites will suffice. If the composite is difficult to remove completely from the wire, then the retainer may need to be replaced. A fractured retainer will require removal and replacement following the usual bonding protocol (Figure 8).

Patients should be advised to return as a matter of urgency if their bonded retainer/s become loose or break. In addition, if comfortable, they should be advised to wear their removable retainer on a full-time basis until they are assessed. This will help maintain tooth position. Full-time wear refers to wearing the retainers all the time except for eating and cleaning.

\section{Effectiveness of different retainer types and wear regimens}

Several published studies have attempted to compare the different types of retainers in terms of clinical effectiveness. Table 4 summarizes the latest systematic reviews on this topic.

There is no universal removable retainer wear regimen. Proponents exist for both full- and part-time wear. Full-time wear regimens often reduce to part-time and some examples include:

- Full-time wear for three months followed by night-only for three months; ${ }^{19}$

- Full-time wear for one week followed by night-only for six months; ${ }^{19}$

- Full-time wear for six months; ${ }^{20}$

- Full-time wear for three months gradually reducing to one or two nights a week. ${ }^{21}$

Some examples of part-time wear regimens include:

Night-only for six months; $;{ }^{20}$ and

Reducing from 10 hours daily in the first six months to one or two nights weekly. ${ }^{21}$

\section{Cost-effectiveness}

One of the important factors to consider when 


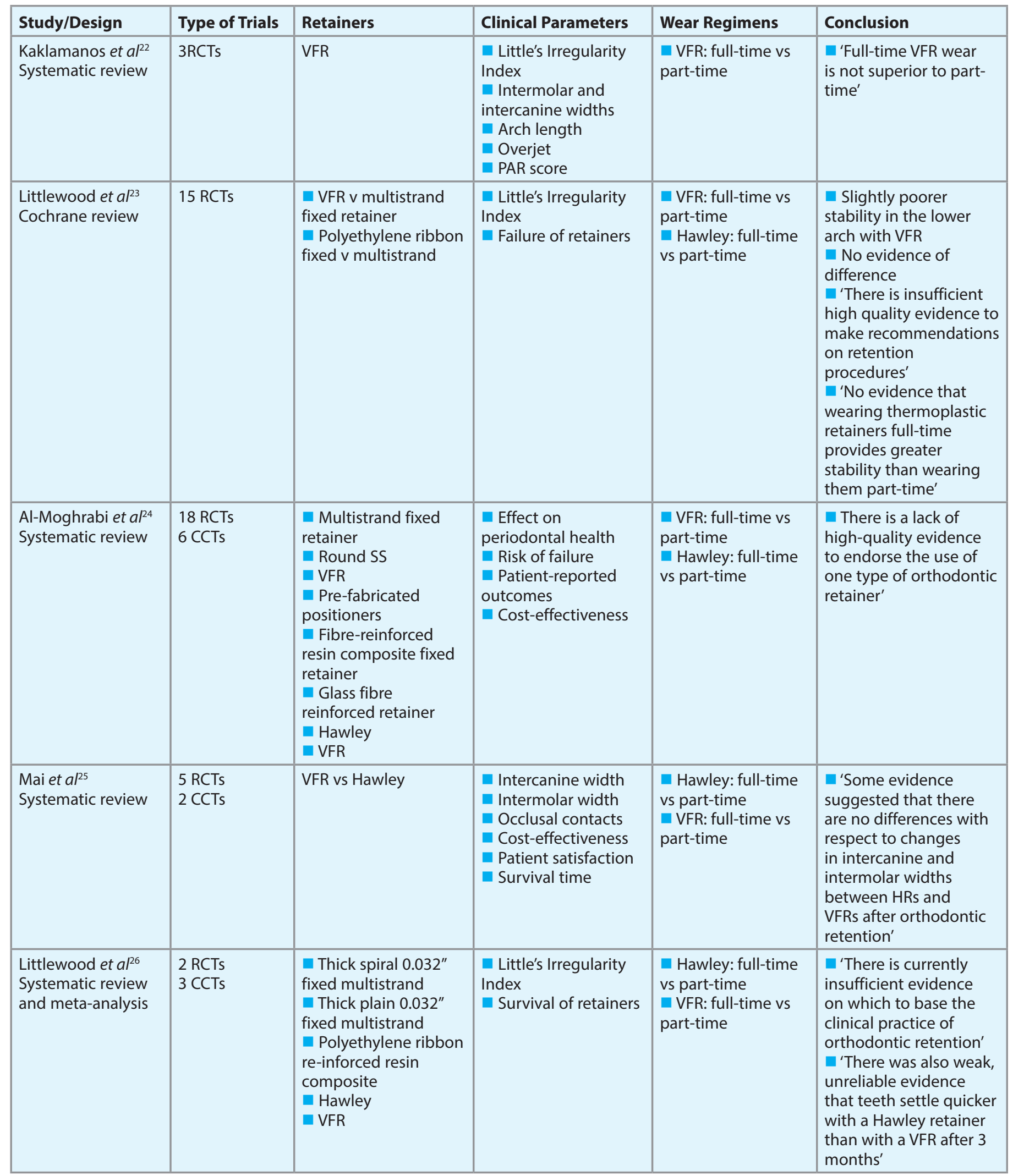

Table 4. Clinical effectiveness of different types of fixed and removable retainers and wear regimens from systematic and Cochrane reviews. RCT: Randomized Controlled Trial; CCT: Controlled Clinical Trial; PAR: Peer Assessment Rating index. 
selecting and prescribing an orthodontic retainer is cost-effectiveness. Regarding the most widely used retainers in the UK, VFRs were found to be more cost-effective than Hawley. ${ }^{27}$ This was not only from the perspective of the patient (mean difference in cost per patient: $£ 4$ ) but particularly the NHS (mean difference in cost per patient to the NHS: £31) and the orthodontic practice (mean difference in cost per patient to the practice: $£ 32){ }^{27}$

Regarding the long-term burden of care, the British Orthodontic Society (BOS) accepts that asking patients to wear retainers indefinitely adds to the 'burden of care'. The patients, however, have to be responsible for wearing and looking after the retainer, as well as getting it checked, repaired and replaced, which may have financial costs. It is therefore essential that this is discussed as part of the process of informed consent at the commencement of treatment and again on placement of the retainers.

\section{Discussion}

Orthodontic retention is essential to prevent unwanted tooth movement. To this end the BOS launched the 'Hold that Smile' campaign in September 2017.28 The campaign has three main elements, a Twitter campaign, two short YouTube information videos produced by the BOS and news articles published on the BOS website. The videos comprise a 'Hold that Smile' animation and a captioned short film which communicate the benefits of using retainers. These are now available for orthodontic and dental clinics to share with their patients:

BOS Retention Campaign -

Hold that Smile; https://www.youtube. com/watch?v=P5FxothkHMg, 2125 views as at 27 June 2018 Hold that Smile - Why are retainers so important? https://www. youtube.com/watch?v=5wCIFjIStzc, 1900 views as at 27 June 2018.

The British Dental Journal recently published an article exploring the BOS initiative on 'Hold that Smile' campaign from a GDP's perspective. ${ }^{29}$ We advise the readers to refer to this article to explore in more depth the role and responsibility of the GDP in post orthodontic retention. A response from BOS discussed in more detail the scientific background that supports the 'Hold that Smile' campaign. ${ }^{30}$

\section{Patient commitment to retainer wear}

Currently there are no accepted guidelines that specify a gold standard/universally accepted retention regimen. However, the BOS encourages patients to adhere to life-long orthodontic retention in order to maintain tooth alignment. It is generally accepted that patients should be encouraged to wear retainers, at least on a part-time basis, for as long as they want the teeth to remain well aligned. Retainer wear is the patient's responsibility and this should be emphasized. Furthermore, long-term maintenance and repair of the retainers should be sought and the patient should be made aware of this commitment prior to starting treatment.

\section{Role of the GDP}

General dental practitioners are integral to the management of the orthodontic patient. Johnston and Littlewood suggested the following notes for the GDPs in relation to retention: ${ }^{31}$

- Informing potential orthodontic patients before referral to a specialist that wearing retainers after orthodontics is an essential part of orthodontic treatment.

- Reinforcing the need for patients to wear their retainers as advised and instruction on how to look after them.

- At dental 'check-up' appointments, ensuring that patients are adhering to their retention regimens as set by the treating orthodontist. Adjustment, repair or replacement of removable retainers and ensuring that they still fit well. (Responsibility for the replacement or repair may depend on whether the patient remains under the care of the orthodontist who completed the treatment).

- For patients with bonded orthodontic retainers, checking that retainers are still intact, bonded and that the patient is maintaining good oral hygiene around them. Fractured or de-bonded retainers should be repaired (with appropriate advice/referral if required).

If at any stage the GDP feels that managing a particular situation is out of his/her personal scope of expertise, then a referral to an appropriately qualified colleague should be made with the information that this care may only be provided on a private basis.

\section{Conclusions}

Current practice dictates that the responsibilities of maintaining retainers and regular reviews are shared between the patient, the orthodontist and general dental practitioner. Close co-operation between all the parties involved is required. Retention is a complex issue and relapse is multifactorial in nature. Retention regimens invariably require considerable patient co-operation, which is usually forthcoming if the patient is fully informed, both before treatment and on placement of the retainers, and understands the planned regimen as well as the need for it.

\section{Compliance with Ethical Standards}

Conflict of Interest: The authors declare that they have no conflict of interest. Informed Consent: Informed consent was obtained from all individual participants included in the article.

\section{References}

1. Melrose C, Millett DT. Toward a perspective on orthodontic retention? Am J Orthod Dentofacial Orthop 1998; 113: 507-514.

2. Horowitz SL, Hixon EH. Physiologic recovery following orthodontic treatment. Am J Orthod Dentofacial Orthop 1969; 55: 1-4.

3. Johnston C, Burden D, Morris D. Clinical Guidelines: Orthodontic Retention, 2008. Revised 2013. www.bos.org.uk Accessed August 2018.

4. Reitan K. Clinical and histologic observations on tooth movement during and after orthodontic treatment. $\mathrm{Am}$ J Orthod Dentofacial Orthop 1967; 53: 721-745.

5. Edwards JG. A long-term prospective evaluation of the circumferential supracrestal fiberotomy in alleviating orthodontic relapse. Am J Orthod Dentofacial Orthop 1988; 93: 380-387.

6. Sadowsky C, Schneider BJ, BeGole EA, Tahir E. Long-term stability after orthodontic treatment: nonextraction with prolonged retention. Am J Orthod Dentofacial Orthop 1994; 106: 243-249.

7. Moss JP. The soft tissue enviroment of teeth and jaws: an experimental and clinical study: Part 1. Br J Orthod 1980; 7: 127-137.

8. Felton JM, Sinclair PM, Jones DL, Alexander RG. A computerized analysis of the shape and stability of mandibular arch form. Am J Orthod Dentofacial Orthop 1987; 92 : 478-483.

9. de la Cruz A, Sampson P, Little RM, Artun J, Shapiro PA. Long-term changes in arch form after orthodontic treatment and retention. Am J Orthod Dentofacial Orthop 1995; 107: 518-530.

10. Kahl-Nieke B, Fischbach $\mathrm{H}$, Schwarze CW. Post-retention crowding and incisor irregularity: a long-term follow-up 
evaluation of stability and relapse. $\mathrm{Br} J$ Orthod 1995; 22: 249-257.

11. Blake M, Bibby K. Retention and stability: a review of the literature. Am J Orthod Dentofacial Orthop 1998; 114: 299-306.

12. Bishara SE, Jakobsen JR, Treder J, Nowak A. Arch width changes from 6 weeks to 45 years of age. Am J Orthod Dentofacial Orthop 1997; 111: 401-409.

13. Sinclair PM, Little RM. Maturation of untreated normal occlusions. Am J Orthod Dentofacial Orthop 1983; 83: 114-123.

14. Artun J, Spadafora AT, Shapiro PA. A 3-year follow-up study of various types of orthodontic canine-to-canine retainers. Eur J Orthod 1997; 19: 501-509.

15. Shaunnesy TG, Profitt WR, Samara SA. Inadvertent tooth movement with fixed lingual retainers. Am J Orthod Dentofacial Orthop 2016; 149: 277-286.

16. Zachrisson BU. The bonded lingual retainer and multiple spacing of anterior teeth. Swed Dent J Suppl 1982; 15: 247-255.

17. Bearn DR. Bonded orthodontic retainers: a review. Am J Orthod Dentofacial Orthop 1995; 108: 207-213.

18. Al-Nimri K, Al Habashneh $\mathrm{R}$, Obeidat M. Gingival health and relapse tendency: a prospective study of two types of lower fixed retainers. Aust Orthod J 2009; 25: 142-146.

19. Jäderberg S, Feldmann I, Engström C. Removable thermoplastic appliances as orthodontic retainers - a prospective study of different wear regimens. Eur J Orthod 2012; 34: 475-479.

20. Gill DS, Naini FB, Jones A, Tredwin CJ. Part-time versus full-time retainer wear following fixed appliance therapy: a randomized prospective controlled trial. World J Orthod 2007; 8: 300-306.

21. Thickett $E$, Power $S$. A randomized clinical trial of thermoplastic retainer wear. Eur J Orthod 2010; 32: 1-5.

22. Kaklamanos EG, Kourakou M, Kloukos D, Doulis I, Kavvadia S. Performance of clear vacuum-formed thermoplastic retainers depending on retention protocol: a systematic review. Odontology 2017; 105: 237-247.

23. Littlewood SJ, Millett DT, Doubleday B Bearn DR, Worthington HV. Retention procedures for stabilising tooth position after treatment with orthodontic braces. Cochrane Database Syst Rev 2016; (1): CD002283.

24. Al-Moghrabi D, Pandis N, Fleming PS. The effects of fixed and removable orthodontic retainers: a systematic review. Prog Orthod 2016; 17: 2-22.

25. Mai W, He J, Meng $\mathrm{H}$ et al. Comparison of vacuum-formed and Hawley retainers: a systematic review. Am J Orthod Dentofacial Orthop 2014; 145: 720-727.

26. Littlewood SJ, Millett DT, Doubleday B, Bearn DR, Worthington HV. Orthodontic retention: a systematic review. J Orthod 2006; 33: 205-212.

27. Hichens $\mathrm{L}$, Rowland $\mathrm{H}$, Williams $\mathrm{A}$ et al. Cost-effectiveness and patient satisfaction: Hawley and vacuum-formed retainers. Eur J Orthod 2007; 29: 372-378.

28. British Orthodontic Society. BOS launches 'Hold that Smile' retention campaign. 2017. Available at https://www.bos.org.uk/ News-and-Events/News Accessed August 2018.

29. McCrory PV. British Orthodontic Society's initiative on orthodontic retention: a GDP's perspective. Br Dent J 2018; 224: 481-486.

30. Littlewood SJ. BOS response to article on 'Hold that Smile' campaign. Br Dent J 2018; 224: 925-936.

31. Johnston CD, Littlewood SJ. Retention in orthodontics. Br Dent J 2015; 218: 119-122.

\section{Beautifil II Gingiva}

- For the reproduction of gingival areas

- Indicated in cases of gingival recession, exposed abutments and crown margins, root erosion and missing papillae

- Shades can be layered and blended for aesthetic solutions without the need for surgery

- Perfect for Class V restorations

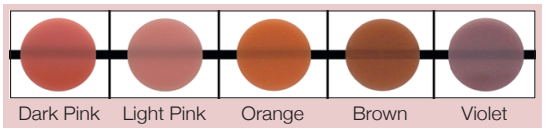

\section{Beautifil II Enamel}

- For direct anterior restorations

- Polychromatic restorations thanks to chameleon effect

- Cost-effective alternative to porcelain veneers

- Highly aesthetic restorations achievable by layering and blending the shades

- Based on porcelain shade concept - for easy shade matching

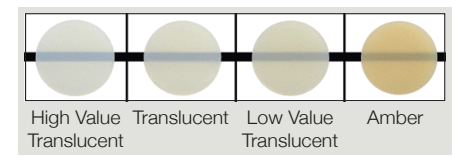

BEAUTIFIL II

Gingiva \& Enamel

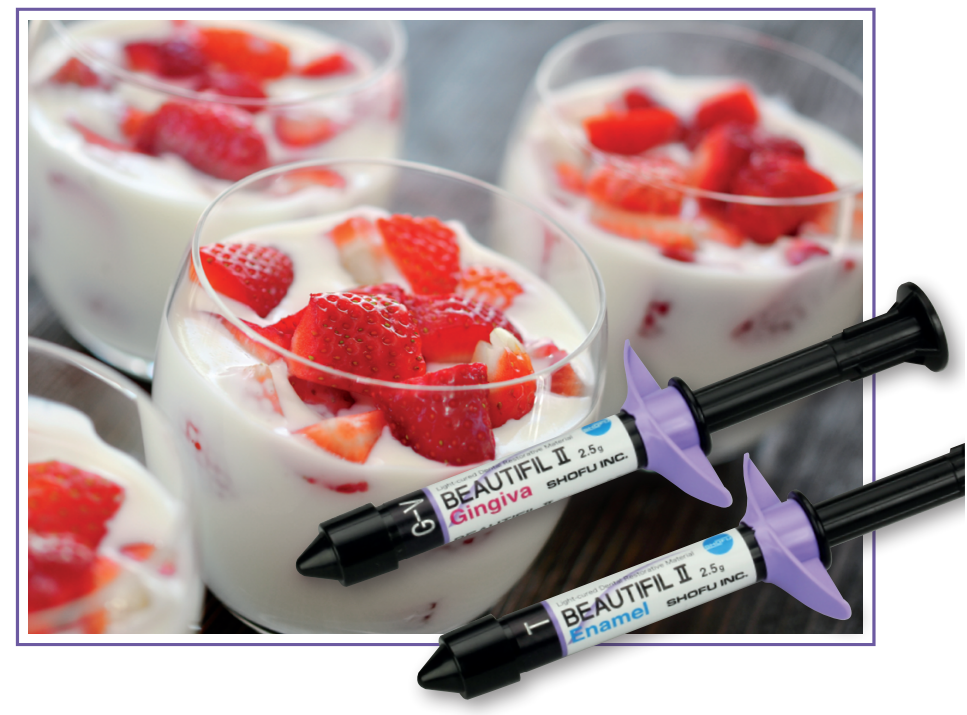

